\title{
XXVII. On the Structure and Homologies of the Renal Organ in the Nudibranchiate Mollusca. By Aubany Hancock, F.L.S.
}

\author{
(Plates LIV.-LIX.)
}

Read June 2nd, 1864.

IN a paper "On the Anatomy of Doris," by Dr. Embleton and myself*, we described what we took to be a portal heart, a peculiar pyriform vesicle situated directly below the pericardium, and opening into it. For reasons stated at the time, we believed that this organ threw venous blood into the liver. My confidence, however, in the accuracy of this determination was much shaken on not finding any similar organ or anything equivalent to a portal system in the Cephalopoda, the study of the anatomy of which has for some time past engaged my attention. Had Doris really possessed a portal system such as we described, surely the more highly organized Cuttlefish should not be deficient in this respect. In the one case or the other it appeared to me that we must be in error. It therefore became necessary to re-examine this point in the Doridida, and in fact to institute in the Nudibranchs generally a more minute investigation than had hitherto been made of the renal organ, with which the so-called portal heart is connected.

With this view I have now completed a rather laborious examination of a large collection of Madras Nudibranchs kindly placed at my disposal by Walter Elliot, Esq., of Wolfelee, North Britain, and which form the subject of a recent communication to the Zoological Society by Mr. Alder and myself $\uparrow$. Some very interesting modifications of these organs have come to light during this investigation; and it is proposed on the present occasion to give a detailed account of them, and to take into consideration the bearing they have upon the question of the existence of a water-system in these animals, and also to examine their homological relation to the similar organs in some other Mollusks, particularly those in the Cephalopods.

In the first instance, however, it is desirable to describe these parts in two or three British Dorides, especially as we had to some extent misunderstood in them the true nature of these organs, and there will thus be afforded an opportunity of correcting one or two errors that occur in our paper before alluded to, the most important of which relates to the pyriform vesicle, which, as already stated, we described as a portal heart.

The vesicle is essentially a portion of the renal organ; it is not related to the liver in the way we supposed; and I am glad of being able on this occasion to correct a mistake which we made, not from carelessness, but after a lengthened and painstaking investigation of the subject. No doubt can exist of the fact as now determined, not only in our British species, but in large exotic specimens and various generic forms in which this organ presents numerous and instructive modifications. In the British species, indeed, this subject is fraught with much difficulty, as well on account of their diminutive size as

\footnotetext{
* Phil. Trans. for 1852 (pt. 1), p. 207.
}

+ Trans. of the Zool. Soc. vol. v. p. 113. 
also from the peculiar way in which the parts are arranged. Even now, after it has been clearly demonstrated that the pyriform vesicle is connected with the renal chamber, it is not always possible to determine the fact in the British species originally examined, namely, Doris tuberculata, D. repanda, D. pilosa, and D. bilamellata.

The examination of a single individual of the genus Scyllae put the matter right at once, which the closest investigation of at least a score of the above species had failed to do. Thus it is evident how desirable it is in all difficult matters of this nature to have recourse to a diversity of examples; for the point that may be most difficult to solve in one may be exceedingly easy in another. On retracting our opinion as to the nature of the pyriform vesicle, it must also be stated that Cuvier was the first to show that this vesicle really opens externally - an assertion which we originally controverted. He, however, seems to have been unaware that it also opens into the so-called pericardium.

In Doris tuberculata, D. repanda, D. pilosa, and D. bilamellata there is a large, more or less ramified chamber or sinus stretching along the dorsal surface of the liver-mass, and having the pericardium lying above it. This, which is the renal chamber proper, is circumscribed by a delicate membrane, distinctly demonstrable above but intimately united with the liver-capsule below ; and in all the species it opens externally by a small pore placed a little above and to the right of the anal nipple, and communicates with the pericardium through the instrumentality of the pyriform vesicle.

In D. tuberculata this chamber is much ramified (Pl. LIV. figs. 1 \& 2); the trunk is rather narrow and extends along the median line from end to end of the liver-mass; it expands a little and reaches backwards to the region of the branchial circle, where its wall becomes firmly adherent to the skin. In front the trunk bifurcates, a branch passing along the right and left margin of the liver. Several ramified branches extend from the sides of the chamber and spread over the surface of this organ. Two or three of these at each side are longer than the rest, and reach for a considerable way round it. There are likewise a few small branches which seem to penetrate the substance of the liver.

The aorta runs forward, adherent to the membranous roof of the right branch of the bifurcation, which is prolonged and accompanies the gastric artery to the stomach, where it ends (as do apparently, as far as they could be examined, all the other branches) in a blind sac. Other arterial trunks from the root of the aorta run in like manner along the roof of the left branch of the bifurcation and that of the several lateral ramifications, while two pass backward in connexion with the trunk of the organ. The great branchiohepatic vein runs backward along the median line under the floor of the chamber, bulging into it, and receiving numerous branches right and left. It reaches beyond the posterior extremity of the liver and becomes isolated within the chamber, and is surrounded by a thick, spongy-looking, glandular tissue, which extends for some distance along the trunk, and pervades the whole of the posterior portion of the renal cavity.

The renal chamber proper in Doris repanda, D. pilosa, and D. bilamellata* is much

* Figures of the renal chamber in these three species are given in the paper before alluded to, "On the Anatomy of Doris," published in the 'Philosophical Transactions.' The minute structure of the glandular lining of the organ is also given. 
less branched than in the preceding species, and on the left side there is an angular lobe, the margins of the whole being somewhat sinuous. In all three the chamber extends from one extremity of the liver to the other; it is rather wide, and its walls are richly supplied with an arterial network composed of twigs from numerous trunks passing from both sides of the aorta, which runs forward in the roof of the chamber. In $D$. repanda these trunks are small and very numerous, and branch off from each side of the aorta with a considerable degree of symmetry. Two trunks, larger than the rest, extend backwards parallel to each other. In D. pilosa and D. bilamellata the arterial plexus is arranged much in the same manner, but scarcely so symmetrically. In the former the network in the roof of the chamber is remarkably rich and minute.

The chamber is lined throughout with a spongy glandular tissue which is thickest over the tracks of the blood-vessels, and presents, particularly in D. repanda, a very peculiar honeycombed appearance, caused by slightly elevated lines of membrane enclosing fiveor six-sided spaces, each holding a single large, clear, globular vesicle, containing a few smaller cells of different sizes, together with some granules.

The so-called pericardium (Pl. LIV. fig. $1, a$ ) lies, as has been already stated, immediately above the renal chamber and directly below the dorsal skin in front of the branchial circle. It is, with the exception of the opening leading into the pyriform. vesicle, a closed membranous sac, formed apparently by what has been designated the peritoneum, and is just sufficiently large for the accommodation of the dilated auricle and. ventricle. It is lined with its own proper membrane, which is closely adherent to, and intimately confounded with, the peritoneal membrane, but can be observed reflected upon the heart at the root of the aorta. It therefore apparently encloses that viscus in a fold somewhat in the manner of a serous membrane. It has just been stated that this cavity is closed. In the paper on Doris before alluded to it was described as communicating with the great abdominal chamber or peritoneal cavity by numerous minute punctures in its floor. I am now satisfied, however, that this was a mistake arising from the specimens examined having been slightly decomposed. The walls of the pericardium, as we have seen, are composed of the peritoneum and the lining membrane: the former in the floor of the organ is comparatively robust, and is provided with muscular fibres mostly transverse; the latter is exceedingly delicate, and the consequence is that, when the specimen is in a soft state and the slightest strain is used, the fibres separate a little from each other, and the lining membrane gives way. Thus small openings occur which have much the appearance of being natural.

The pyriform vesicle (Pl. LIV. figs. $1,2,3$ ) in some species is nearly half the size of the contracted ventricle, and, as already stated, connects the pericardial chamber with the renal chamber proper. It lies transversely between these two organs towards the right side, with the rounded extremity opening upwards through the floor of the pericardium immediately in front of the right angle of the auricle, close to the point where the latter receives the great vein from the skin. The aperture is circular, and is apparently capable of being closed as if by a sphincter. The narrow extremity of the vesicle seems to penetrate the roof of the renal chamber on the right side towards the posterior end, and, bulging into the organ, becomes cemented as it were to the floor of the chamber. 
In Doris tuberculata it is prolonged into a tube (Pl. LIV. fig. 2), which, turning forwards, runs along the median line almost to the anterior extremity of the trunk-portion of the cavity, where it opens into it by a slit-like orifice. The tube overlies and partially conceals the great branchio-hepatic vein, and is liable to be confounded with its branches and with the divisions of the oviduct, which in certain conditions is also apparent through the floor of the renal chamber. It was by the complication produced by all these branches and by those before mentioned, which form a network in the walls of the chamber, that we were originally deceived into the belief that the tubular prolongation of the vesicle was itself branched, and was in this way connected with the liver.

It is above stated that the vesicle seems to penetrate the wall of the renal chamber. It does not in fact do so, but passes between it and the liver, and bulges so $^{3}$ far into the cavity as to appear to have passed into it, especially as the floor of the chamber is so extremely delicate as to be scarcely, if at all, demonstrable. Hence it is that the vesicle and its tubular prolongation have the appearance of being adherent throughout to the floor of the organ.

The wall of the tubular prolongation is delicate and glandular. The vesicle itself has a firm, compact appearance, and is generally of a brownish-yellow colour. It is supplied with muscular fibres, which stretch in all directions throughout its walls; and there is also a distinct belt of similar fibres surrounding the orifice opening into the so-called pericardium, which no doubt will act as a sphincter to guard this passage of communication. The muscular belt was very distinctly observed in Tritonia Hombergii. The inner surface of the vesicle is strongly plicated longitudinally, the plicæ being furnished with lateral laminæ, and the whole so arranged in many cases around the orifice leading into the pericardial. chamber as to act as a sort of valve to prevent fluid returning into the latter from the vesicle. The plicæ and their laminæ are covered with large vibratile cilia, which are inclined from the orifice inwards, probably for the purpose of sweeping fluid from the so-called pericardium into the vesicle. Each cilium projects from the pointed extremity of an ovate vesicle, which is filled with minutely granular matter. The broad ends of the vesicles are crowded together and assume an hexagonal form, clothing everywhere the plicæ with a sort of pavement-epithelium (Pl. LIV. fig. 6 and Pl. LV. fig. 4). The ciliated epithelium is very deciduous, and can only be observed when the specimen is in a good state of preservation. It has been detected, however, in Doris tuberculata and in some other species. It occurred in a very perfect condition in Tritonia Hombergii, in which the cilia are unusually large, measuring about $\frac{1}{200}$ th of an inch in length.

There is no remarkable difference in the character and arrangement of the pericardial chamber and the pyriform vesicle in $D$. bilamellata, $D$. repanda, and $D$. pilosa, except that in the first the glandular prolongation of the vesicle is continued quite to the anterior margin of the liver, where it terminates in an opening placed a little to the right side, and that in the last the prolongation is entirely deficient (PI. LIV. fig. 3), the narrow extremity of the vesicle opening at once by a widish orifice into the renal chamber. This orifice is placed close to the floor of the chamber, so that it is overhung by the projecting wall of the vesicle; thus a sort of valve is provided which will prevent any fluid 
passing from the renal into the perieardial chamber. The valvular nature of the passage is still more obvious in those species which have the apex of the vesicle prolonged into a tube, as in $D$. tuberculata. Here this tubular passage is related to the renal chamber exactly as the ureters are to the bladder in the higher animals.

Having now completed our examination of the renal organ in a few British Dorides, we may safely conclude that in these animals it is composed of two principal parts, namely the pericardial chamber and the renal chamber proper, which are brought into communication by the agency of a third part, the pyriform vesicle, with or without its tubular prolongation. We shall now endeavour to ascertain how far these parts are modified in the different Nudibranchiate forms, using chiefly in our examination the exotic species before alluded to.

In Doridopsis, a genus of a new family which we have recently established* for the reception of certain Doris-like mollusks with suctorial, proboscidiform mouths destitute of any armature whatever, the renal organ does not present any very striking modification.

The renal chamber proper (Pl. LV. figs. 1 \& 2) in this genus occupies the usual position on the dorsal surface of the liver; it is of an irregular form, is rather wide, but does not branch over that viscus as it does in Doris tuberculata. A few small branches, however, apparently penetrate its substance. I have not detected the vascular network in the walls of the chamber, nor the glandular matter lining the interior: but these features can be observed only under favourable circumstances; they may therefore exist, though they have hitherto escaped detection.

The pyriform vesicle is unusually large, firm, and well developed. The narrow extremity, which lies within the renal chamber, and is adherent to its floor, ends abruptly a little in advance of the external opening, and is perforated. The perforation is large, and is placed at the junction of the lower wall of the vesicle and the floor of the chamber. The upper, overhanging wall of the vesicle will consequently act as a valve, as it does in D. pilosa, and prevent any fluid from passing out of the renal chamber into the vesicle and consequently into the pericardium. The laminæ in the interior of the vesicle (PI. LV. fig. 3) are well developed, and extend the whole length of the organ; they are delicately pinnate.

The walls of the pericardial chamber are thicker than usual, and the lining membrane is raised along the anterior margin of the roof into numerous longitudinal folds, which in some of the species extend nearly half the length of the organ backward. They are of an opake yellow colour, and have a glandular appearance.

The renal organ in Tritonia Hombergii exhibits no important modification. The small external opening is placed on the right side of the animal, directly above the anal nipple, and leads by a short tube, scarcely longer than the thickness of the skin through which it penetrates, into a large irregularly formed renal chamber, that lies beneath the pericardium, resting upon the anterior portion of the liver. The vesicle connecting the pericardial with the renal chamber is placed towards the right side; it is very large, being scarcely less than the ventricle when in a contracted state, and is somewhat cylin-

* Trans. Zool. Soc. vol. v. p. 124. 
drical in form, about as wide as long, with the ends flattened; it. is strongly plicated in the interior, and has attached to it a tubular prolongation (Pl. LIV. fig. 5): but the character and extent of this appendage were not ascertained; and, indeed, several points $i_{n}$ connexion with the renal organ in this form require a fuller examination than, on account of the deficiency of specimens, I have been able to give them.

The first form in which we observe any marked change in this complicated apparatus is Hexabranchus gloriosus*. In this magnificent Nudibranch the renal chamber proper (Pl. LVI. fig. 1) is much reduced in size, and has assumed a tubular form of limited width, stretching almost from end to end of the liver, along the median dorsal line, parallel to and on the right side of the great branchio-hepatic vein. It tapers a little backwards to the external orifice (which is situated directly above the anal nipple), and is connected with the pyriform vesicle by a short wide tube.

On laying this tubular chamber open (Pl. LVI. fig. 2), however, it is found not to be a simple tube, but to have numerous branches of various sizes passing from either side, which for the most part follow the trunk arteries that ramify over the surface of the liver, but their exact course and extent were not determined. Small orifices in the floor of the organ indicate that branches also dip into the substance of the liver.

Immediately beneath the floor of the chamber, and bulging into it, is observed the tubular prolongation of the pyriform vesicle. It is almost as wide as the chamber itself, and, bending forward, stretches nearly as far as its anterior extremity, where the prolongation opens into it by a slit-like orifice. On laying this tube-like organ open (PI. LVI. fig. 3), the inner surface is seen to be thickly studded all over with erect, firm, dendritic tufts (fig. 4), which are coated, as well as the surface to which they are attached, with minute granular cells.

In Plocamophorus Ceylonicus, one of the Polycerida, the renal organ undergoes a still more remarkable change ( $\mathrm{Pl}$. LV. fig. 5). In this species the narrow extremity of the pyriform vesicle gives off, as it were, two tubes of no great width. One $\left(r^{\prime}\right)$, which is the wider of the two, turns backward, and, after running for a little way in contact with the upper surface of the intestine, tapers as it terminates at the pore by the side of the anus: the walls of this tube are delicate and transparent. The other tube $(j)$ extends down the left side of the liver, in a cleft dividing the anterior and posterior lobes. In its course it passes over the great branchio-hepatic vein, to the wall of which it is firmly adherent, and after running for a short way in contact with the intestine, which issues from the same cleft, it tapers gradually and terminates in a cæcal extremity. Throughout its whole length it is lined with a yellowish glandular matter, which in places becomes broken up into irregular nodules. These two tubes are the sole representative of the renal chamber, which we have seen so extensively developed in some of the other forms. It has now assumed the character of a crecal gland with a tubular external outlet, which is in connexion with the pyriform vesicle.

The laminæ in the interior of the pyriform vesicle are very ample, but become abruptly curtailed as they approach the lower or pointed extremity of the organ; they are thence

* This is the Doris gloriosa of Kelaart, in the Journal of the Ceylon Branch of the Royal Asiatic Society. 
continued, much reduced in size, for some distance down the cæcal tube. The pericardial chamber presents nothing peculiar, except that it is unusually large.

In the form now before us the renal organ is comparatively simple in its structure; but in those that are to follow, much complication will be observed; nevertheless, in them, as well as in the former, it is distinctly divisible into the two principal component parts, which we have seen to exist in all the species examined. An interesting example of this complicated condition of the organ is found in Bornella digitata, a very curious animal from the Indian seas, closely related to Dendronotus.

The pericardial chamber (PI. LVII. figs. $1 \& 6$ ) in this species presents nothing remarkable; neither does the pyriform vesicle, though it opens into the former further backward than usual, and close to the right side, under the auricle. It is the part designated as the renal chamber proper that exhibits the interesting and extensive modifications alluded to. This portion of the renal organ (figs. $1 \& 2 j$ ) assumes the form of a long, wide tube, with delicate, almost transparent walls, extending along the dorsal surface of the viscera nearly from one extremity of the body to the other. In front this tube lies beneath the pericardial chamber; and at this point it bifurcates, the two branches being almost as wide as the trunk. The left branch lies above the stomach, the right above the reproductive organs. The pyriform vesicle penetrates the trunk, and opens into it close to the point where the bifurcation takes place; and immediately behind this a slender tube is given off from the right side, which passes along the dorsal surface of the rectum, and terminates at a minute orifice immediately above the anal nipple.

The whole of this tubular chamber, including the anterior bifurcation, gives off from both sides numerous slender offsets, which for the most part bend downwards and, embracing the viscera, ramify over them. These ramifications terminate in blind sacs, and have their extremities occasionally rounded and enlarged. The branches are not adherent to the organs upon which they rest, but lie free amidst the loose cellular tissue that binds the viscera to the skin; and many of the terminal extremities penetrate the intermuscular spaces of the foot, others follow the gastro-hepatic branches into the base of the branchial papillæ. The posterior trunk terminates, close to the extremity of the visceral mass, in a ramified branch similar to the lateral branches, and the members of the anterior bifurcation end in the same manner not far behind the buccal organ.

This much-ramified organ is lined throughout with a coating of opake, pale, granular matter, composed of minute cells. In the trunk this coating is very thin, but is much thicker in the branches (Pl. LVII. figs. 4 \& 5), where it is thrown into longitudinal folds ; consequently the latter, on account of their opacity, are more conspicuous than the former, though this is very much larger.

Now it is quite evident that we see, as it were, in this beautifully developed organ an unravelled gland, which, from its peculiar structure, throws much light on the nature of this organ in the species previously described. In Bornella it is no longer combined with the liver-mass (which in this form is broken up), though partially retained in the visceral chamber. Owing to this fact the gland is distinctly visible in all its parts, and it is perfectly clear that it is in no way anatomically or functionally connected with the

vol, XXIV.

$3 \mathrm{x}$ 
liver. Thus we may assume that it is also distinct in those species in which it is more or less confounded with that viscus. In these latter it is difficult, if not impossible, to follow all the ramifications of the organ as they branch over and into the substance of the liver; and had it not been for the aid afforded by this and the following interesting example, doubts might have existed as to the relation of the two organs.

In the higher Nudibranchs the connexion of the renal chamber with the liver arises, apparently, from the arrangement of the vascular system, which in them is more highly developed than in the lower forms. In the former there are both hepatic arteries and veins; and these, we have seen, have a certain relation to the renal chamber. It is over the hepatico-branchial vein, which protrudes into the chamber, that in Doris tuberculata the glandular matter is accumulated; and the rich vascular network that pervades the walls of the organ is derived from the hepatic arteries. Hence the connexion of the two organs. In Bornella, which is one of the lower forms, neither the hepatic arteries nor veins exist; the renal gland is consequently detached from the liver, which in this species is found only in a rudimentary state in the visceral chamber. We have seen, however, that the gland overlies the viscera, and to a great extent embraces the rudimentary hepatic organ, following its ramifications even into the branchial papillæ, retaining, as it were, a lingering connexion with this viscus, though it must now derive its blood from that which bathes the visceral chamber.

In Dendronotus the kidney is apparently formed on the same plan as in Bomella; but the details of the organ could not be made out, though the posterior trunk of the renal chamber was observed.

Another distinct glandular form of the renal chamber is found in Scyllaea. In a member of this genus from Madras, and described under the name of S. marmorata* ${ }^{*}$, the development of this organ is very remarkable. The pericardial chamber (Pl. LVIII. fig. 2) presents nothing uncommon; the pyriform vesicle, however, opens into it further forward than usual, on the right side, immediately in front of the auricle, and, passing downwards, has its lower or tapering extremity united to a tube which lies on the upper surface of the rectum (Pl. LVIII. fig. 1). This tube passes to the right side, and soon terminates in the minute opening associated with the anal nipple (fig. 6). The other or inner extremity of the tube bifurcates immediately to the left of the vesicle, one branch turning forward, the other backward. The former passes under the intestine, giving off branches as it goes, to the under side of that tube, to the gizzard, and to the anterior ovarian mass; it then branches over the dorsal aspect of the stomach, and sends a branch or two to the reproductive organs. All these branches terminate in blind sacs, and lie freely in the cellular tissue in connexion with the various organs ; the branch, however, that goes to the ovarian mass is more intimately attached to the surface of the organ, and forms minute and beautiful dendritic ramifications over it. The posterior branch of the tube passes backwards along the dorsal surface of the liver, towards the right side, and distributes offsets to the two posterior ovarian masses, and sends numerous dendritic ramuscules to both the upper and under surface of the liver. The hepatic ramuscules lie loosely attached to the surface of the organ, and all their twigs end in blind sacs like

\footnotetext{
* Trans. Zool. Soc. vol. v. p. 136.
} 
those of the anterior branch. They can be easily raised by the point of a needle; so that their structure is not difficult of demonstration. The ovarian branches spread out over the surface of the masses in numerous dendritic systems, similar to those on the anterior mass. These ovarian ramuscules (Pl. LVIII. fig. 3) are much more delicate than those of the other viscera, and, unlike them, are closely adherent to the surface of the organ, but do not apparently penetrate below the surface.

The whole of this complicated system of branched tubes is glandular throughout. The walls of the branches are minutely folliculated (Pl. LVIII. fig. 4), and lined with a very finely granular matter, composed chiefly of granular cells (fig. 5). The trunk tubes are also lined with the same substance, which gives to the whole system an opake yellow colour; hence the facility with which the minutest ramifications can be traced to their terminations.

The renal organ in Scyllcea pelagica is provided with the same curious ramified gland; only it is less complicated in its structure. We originally mistook some of the branches of the renal gland in this species for a portion of the gastro-hepatic system*, which does not apparently exist in this genus.

On comparing this ramified gland in Scyllaa with that in Bornella, the resemblance is so obvious that no doubt can exist as to their homological relation. It is interesting, however, to observe how intimately the ramifications of the gland in the former are connected with the liver and ovary, though modified in this respect from what obtains in the Dorides. In Scyllaa the liver is broken up into two portions, and the ovary is detached from it in the form of three globular masses. But the vascular system is not degraded to the same extent as it is in Bornella: both the hepatic and ovarian masses are supplied with arteries; hence the ramifications of the gland maintain, to some extent, their connexion with the liver and ovary-particularly with the latter, to which, we have seen, the ramifications are closely adherent.

We have now traced the modifications of the kidney through various forms of the Nudibranchiata, and find that in all, however diversified, the organ is divisible into two principal portions, namely the pericardial chamber and the renal chamber proper; and in addition to these, there is always present the accessory organ the pyriform vesicle. The first and last of these, as far as we have examined, exhibit no material modification, save that the pyriform vesicle is oceasionally prolonged into a glandular tube. The renal chamber proper, however, is considerably diversified in the several forms we have had before us. In Doridopsis and Tritonia we have seen that it is of a wide, irregular form, almost devoid of ramifications. In the Dorides it is still a wide sinus or chamber, but more or less branched; and in Plocamophorus it has assumed the character of a simple tubular gland; while in Bornella and Scyllaa it becomes extremely developed, pervading nearly all the organs of the body by its numerous ramifications-is in fact, in these two last forms, a diffused gland, varying only in the mode of branching. In Bornella the branches have a bilateral symmetry, the centre tube being wide; in Scyllaa there is no apparent order in their distribution, and they are tubular throughout, with the trunk or stem only proportionately larger than the rest.

* Monograph of the British Nudibranchiate Mollusca, Fam. 2, pl. 5. 
The nature of this complicated organ in the Nudibranchs can scarcely be doubted. It is clearly an apparatus for eliminating something from the blood that has to be expelled out of the system; and from analogy this matter may fairly be assumed to be urinary. The renal chamber proper is a glandular organ, as demonstrated in the Dorides; and in Bornella and Scyllaca it has assumed the form of a true gland. It is therefore probable that by this portion of the apparatus, and also by the glandular portion of the pyriform vesicle, the more strictly urinary matters are abstracted, the pericardial chamber furnishing serum or perhaps little more than pure water, which may be supposed to exude from the heart, particularly from the auricle, the walls of which are exceedingly delicate.

The pericardial fluid will be drawn into the pyriform vesicle by the agency of the vibratile cilia clothing the plicæ; the sphincter muscles will then come into play, closing the communicating orifice, and the contained fluid will be forced by the pulsatile action of the organ (the walls of which we have seen to be muscular) into the trunk tube or central portion of the renal chamber, where it will mingle with the more solid urinary products of that organ, and be expelled along with them through the minute pore associated with the anal nipple. That this is the probable action of these parts is evinced by what may be observed in living Nudibranchs. I have frequently seen, in small, transparent individuals, vibratile cilia in motion, at the orifice of a vesicle having the appearance of this pyriform organ; and the vesicle itself may occasionally be observed to contract. But, however this may be, it is evident enough that the pyriform vesicle is for the passage of fluid from the one chamber to the other.

It is worthy of remark that in the higher Nudibranchs, as in Doris for instance, the essentially urinary matters are abstracted from the blood that circulates in the livermass, which is composed of the liver and ovary, there being a special arrangement of the vascular system in connexion with the renal chamber for the purpose; and this is the only blood of the entire animal that passes through the special aërating organ. In the lower forms these matters are eliminated from the blood that circulates in the visceral chamber, consequently from the general supply previous to its return to the vascular centre. Hence it may be inferred that in the former case the organ is more highly specialized than in the latter, in which it is extremely diffused. In Scyllaa the kidney holds a middle position in this respect; for though the ramifications of the organ are extensively distributed, a considerable number of the branches are nevertheless intimately connected with the liver and ovary, particularly with the latter; they therefore probably have some relation to the blood-system in these organs. Many of the branches, however, lie free in the interstices between the viscera.

Such being the function of this enigmatical apparatus, it can scarcely be supposed to perform the work of a water-system as generally understood. M. Milne-Edwards suggests, in his "Observations sur la Circulation," article premier, in the "Annales des Sciences Naturelles,' 1845, "that the pore which exists by the side of the anus, in Doris, may be for the purpose of admitting water into the interior of the organism, there to be directly mixed with the blood." In our examination of the organs in connexion with this pore, we have seen nothing to warrant this belief; on the contrary, the anatomy of the various parts militates against it. We have seen that the renal organ forms a closed 
system, nowhere communicating with the vascular organs, and that any water admitted into it must remain there. Indeed no water could penetrate further than the renal chamber proper; for the passage connecting it with the pericardial chamber is, as we have seen, of a valvular nature, and would act as the ureters do in the higher animals on there being any pressure of fluid in the renal chamber. This is particularly the case where the pyriform vesicle terminates in a tubular prolongation. Now we are aware that this chamber is glandular, and that in Bornella and Scyllea it has assumed the form of an extensively ramified tubular gland, into which it cannot be supposed that water would be admitted from the exterior, any more than it should be into the salivary or any other gland opening externally.

Having now concluded a rather lengthy examination of these complicated organs in the Nudibranchiata, the first thing that strikes us is the great resemblance they bear to the renal apparatus in the Lamellibranchs. In both, the heart is enclosed within a so-called pericardium, which communicates with a glandular organ that opens externally. In the Lamellibranch the latter is double, being composed of two lateral glands which open through the floor of the pericardium by two distinct orifices placed at the sides in front. The glandular organ (or renal chamber proper) in the Nudibranch is single, and placed symmetrically on the central line. This therefore can scarcely correspond to the former (the organs of Bojanus), but in the Lamellibranch would seem to be represented, in part at least, by the point where these two organs open into each other on the median line below the pericardium. Is there, then, anything in the Nudibranch that can be considered homologous with the organs of Bojanus? We have seen that the pyriform vesicle, with its glandular prolongation, is placed at the right side of the animal, and opens on this side through the floor of the pericardium. It is therefore a lateral organ, apparently single only on account of a deficiency of symmetrical development. Were the left-side vesicle present and placed in communication with the pericardium, at a point corresponding to the opening on the right, the arrangement of the parts would be so similar to that observed in the Lamellibranch that there could scarcely be any hesitation in pronouncing the vesicle, with its glandular prolongation, and the organ of Bojanus homologous. We might therefore at once assume that the latter is the true representative of the former, differing principally in extent of development, were we not warned by the presence of the external outlet of the renal chamber proper, which assuredly corresponds to the similar orifice of the right organ of Bojanus.

Now, taking this orifice as one fixed point, and the orifice opening into the pericardial chamber as another, it is quite possible, as Professor Rolleston has kindly suggested to me, that all the anatomical parts that lie between them, including the renal chamber proper and the pyriform vesicle with its glandular prolongation, may correspond homologically to the right organ of Bojanus-or rather that the renal chamber proper represents the right organ of Bojanus, and the pyriform vesicle the constricted passage of communication between it and the so-called pericardium.

The principal reason against this conclusion is found in the fact that the renal chamber proper is usually placed symmetrically on the median line, and is apparently therefore not a lateral organ. In our present state of knowledge, however, it is not easy to deter- 
mine which view is correct. Nevertheless enough has been ascertained to satisfy us that the renal organ in the Lamellibranchiata and Nudibranchiata correspond pretty closely, so far as we have, up to this moment, compared them.

Professor Rolleston and Mr. Robertson, however, have recently described*, in addition to the parts above alluded to, what they consider a water-vascular organ-a minutely ramified system of tubes or vessels in connexion with the reproductive organs, which seems not only for the discharge of the products of these organs, but also for that of water supposed to be drawn into the economy through the orifices leading into the organs of Bojanus by the agency of the pericardial sinus. As this system of aquiferous vessels opens, in numerous instances, into the organ of Bojanus, it may be looked upon anatomically, I presume, as a development of the kidney; and if so, we cannot but be reminded of the highly ramified condition of the renal chamber in Bornella and Scyllca. This may be a mere analogical resemblance, but it is very striking and worthy of a passing remark.

A still more important discrepancy, however, appears to exist. The above authors point out, in their valuable paper already alluded to, that the pericardial sinus is the instrument through which water from the exterior finds its way into the blood-vascular system. In the Nudibranchs we have seen that the pericardial chamber is closed, with the exception of the orifice leading into the pyriform vesicle. We should therefore scarcely expect that in the Lamellibranchiata this same chamber would communicate with the vascular system.

Moreover it is not easy to understand how water absorbed in this way could escape being contaminated with the deleterious urinary or other excretory matters it would assuredly meet with in the organ of Bojanus. And there is also, apparently, a mechanical difficulty in the way of the pericardial sinus acting as a suction-apparatus. The heart in a living state so completely fills the pericardial sinus that there is no space for any considerable influx of fluid. In Anodon the ventricle rolls against the wall of the cavity with such force that, on laying the latter open during life, the former bulges out through the incision. Indeed the pericardial wall follows the action of the heart during its diastole and "systole, as it does likewise in the Nudibranchs. The pericardium is consequently always in a state of repletion; and the only effect the opening of the shell-valves could have would be to permit of a more unrestrained action of the heart. Nothing approaching to a vacuum can be formed by the action of an apparatus such as this.

In saying this I do not mean to deny the possibility of water entering directly into the blood-vascular system in the Lamellibranchs; only it seems unlikely that it should be received in the manner described in the memoir referred to. M. Lacaze-Duthiers described some time ago the existence, in Dentalium and Pleurobranchus, of pores by which the vascular system communicates directly with the exteriort. In Pleurobranchus this opening is situated at the root of the branchial vein, and leads almost directly into it, as can be proved by any one who will take the trouble to examine for himself. This is a very startling fact, and it is interesting to know that it coexists with a renal system

* Phil. Trans. vol. clii. p. 29.

+ Ann. des Sci. Nat. $4^{\mathrm{e}}$ série, Zool. t. vii. p. 5, and t. xi. p. 200. 
arranged after the same manner as that in the Nudibranchs. In Pleurobranchus there is the same closed pericardial chamber (Pl. LIV. fig. 4), communicating through its floor with a long glandular tube, the anterior extremity of which is swollen a little and corresponds to the pyriform vesicle. The tube tapers to the other extremity, which, passing backwards, opens into a large renal chamber that communicates with the exterior through a small pore situated immediately below the gill. This tubular connexion between the pericardium and the renal chamber seems to have escaped the notice of M. LacazeDuthiers.

The coexistence of this opening in the branchial vein along with a renal organ so constructed makes it more unlikely that water should be received into the interior through the agency of the latter organ, in either the Lamellibranchs or Nudibranchs. We should rather look for some special means for the admittance of fluid from the exterior, if, indeed, water be absorbed directly by the vascular system in either of these two Molluscan groups.

In the Nudibranchs we have seen that the renal organ is divided into two principal chambers, the pericardial and the renal chamber proper, and that these communicate with each other through the agency of the pyriform vesicle. The renal organ in the Lamellibranchs is likewise divisible in the same way into two portions. And it is interesting to remark that the Brachiopods also have the renal organ composed of two wellmarked divisions-namely, the great perivisceral chamber with its extensive ramifications, and the renal organ proper or the oviducal passages.

This twofold character is also distinctly observed in the Cephalopoda. In this class of highly organized Mollusks the two renal chambers are extensively developed; and on comparing them with the corresponding parts in the Nudibranchs, many curious and instructive modifications will be observed. The renal chamber proper (PI. LIX. fig. 2) is placed towards the underside of the body, and opens externally into the branchial chamber by two nipple-formed orifices. This is the pseudopericardium of authors. It, however, never contains the heart, but, along with other organs, always the venæ cavæ with their glandular or renal appendages. In the Octopodide it contains usually only these latter organs, and is divided longitudinally by a membranous septum into two lateral halves.

This chamber communicates with another, the genital, by two lateral passages. The genital chamber occupies the posterior extremity of the body, and is extensively developed in the Loliginida, in which it always contains the male or female secerning organ, the stomach, cæcum, and the branchial hearts. In the Octopodide it contains the abovenamed reproductive organs only. This chamber is the equivalent of the pericardial chamber in the Nudibranchs.

Now, the first thing that strikes us on comparing these with the corresponding parts in the Nudibranchs is the bilateral symmetry which they exhibit in the Cephalopoda. In the Nudibranchs we have seen that there is but one external orifice, and that it is placed towards the right side of the anus, the left being atrophied. In the Cephalopod, on the contrary, there are two such orifices, and they are situated symmetrically towards the sides, with the intestine between them. In the Nudibranchs, again, there is but one 
passage of communication between the two chambers, and it is also placed towards the right side, while in the Cuttlefish there are two similar lateral passages symmetrically placed. In the Octopod, too, as just stated, the renal chamber is divided on the median line into two lateral halves. Much of this bilateral symmetry we have seen to exist in the Lamellibranchs, in which there are two external openings and two passages of communication between the chambers. Its absence, however, in the Gasteropodous Nudibranch is what might be looked for, and in no way militates against the homology of the parts.

But the presence of this symmetry in the Lamellibranchs and Cephalopods has nevertheless a certain bearing upon the relation of these organs in the Nudibranchs. It seems, in fact, to favour the opinion previously alluded to as expressed by Professor Rolleston on this subject; for if we assume that the two lateral halves of the renal chamber in the Octopod, with their two passages of communication and two external outlets, represent the two organs of Bojanus, it would appear probable that the renal chamber of the Nudibranch is the homologue of the right organ of Bojanus, and that the pyriform vesicle is nothing more than the right passage of communication between the two renal chambers, whether of the Lamellibranch or of the Cephalopod.

In the next place, the relative situation of the renal chamber to the other viscera is very dissimilar in the Nudibranchs to that in the Cephalopods. This is very striking at first sight, but on a little consideration any doubt as to the homology of the organs on this score is readily removed. To judge fairly in this matter we must imagine what would take place on transforming the Nudibranch into the Cephalopod. To enable us to do so, we must place the former with its head downwards, and suppose the foot developed round the oral orifice ( $\mathrm{Pl}$. LIX. figs. 1 \& 2). The intestine must then be bent forward so as to bring the anal nipple towards the head, carrying along with it the renal chamber proper and its external opening to the under or opposite side of the liver. And now, if the pericardial chamber be developed upward and backward, we shall see that the two renal chambers have assumed their Cephalopodous positions. Their contents, however, are very different; but this is apparently not of much consequence, for in the Cephalopods themselves they do not always contain the same organs.

In the Octopodida the genital chamber holds only the ovary or testis, according to the sex, while the same chamber in the Loliginide usually contains, in addition to these organs, as before pointed out, the stomach, creum, and branchial hearts, with their appendages; though in Sepia one-half of the stomach and the whole of the cæcum are excluded. Again, in the Octopodida the renal chamber or pseudopericardium has occasionally protruding into it the upper or convoluted portion of the intestine, and always the venæ cavæ with their renal appendages. In the Loliginida this chamber invariably contains, in addition to the venæ cava and their appendages, the hepatic ducts with their appended pancreatic glands, and in Ommastrophes, as well as these, the lower portion of the intestine and the greater part of the ink-bag, while in Sepia it likewise holds half the stomach and the whole of the spiral cæeum.

It apparently therefore depends in a great measure upon the extent and direction of the development of these chambers what organs they enclose. Consequently we ought 
not to be surprised at finding that the homologous chambers in the Nudibranch and Cephalopod contain dissimilar organs. This, however, is applicable more particularly to the pericardial chamber of the former, in which the heart is lodged. But we have seen that this chamber is developed upwards and backwards in the Cephalopod, and is consequently drawn away from the heart, which occupies a position between the two chambers. Now, were the ovary and stomach pushed in the same direction, it is easy to understand how they might become enveloped in the membranous wall of the chamber, and ultimately enclosed within its cavity.

The renal chamber proper in the Nudibranchs lies in contact with the intestine and the hepatico-branchial vein, which latter is the representative in these animals of the venæ cavæ of the Cephalopods. The lower portion of the intestine indeed is partially enveloped by the walls of the chamber. There is therefore no difficulty here; for by a slight modification in development both these organs might be thrust into the chamber, and, from the change of the relative position of the stomach and liver that has taken place in the Cephalopod, it is obvious that the hepatic ducts might likewise be enveloped by it; and so with the several other organs.

If, then, this reasoning be correct (and it seems scarcely possible to doubt it), the renal chamber in the Nudibranch is the homological representative of the pseudo-pericardium or renal chamber proper of the Cephalopod, or rather perhaps of the right half of it, the left half, together with its external outlet and passage of communication, having been atrophied in the Nudibranch. In both animals this chamber opens externally, and in both it communicates with another chamber,-in the Nudibranch with the so-called pericardium, and in the Cephalopod with the genital chamber-which two latter chambers are also homologous. The pyriform vesicle is apparently a mere enlargement of the tubular passage of communication between the two chambers. In the Octopodida there is a not very dissimilar enlargement of this tube, but apparently for a different functional purpose.

It thus appears that in both the Nudibranchs and the Cephalopods the renal organ is extensively diffused throughout the organism, and that it is universally divided into two portions or chambers, one of which, the renal chamber proper, is more or less glandular, and has the office, through the agency of secerning cells, to eliminate from the blood the deleterious urinary matters. This is apparently its special function, though it would seem in many instances also to have, in common with the other portion or chamber (the so-called pericardium in the Nudibranch, and the genital chamber in the Cephalopod), to act as a receptacle for the superabundant fluids, perhaps little more than water, that may be supposed to exude from the tissues of the various contained organs.

This duality of the kidney we have seen also to exist in the Brachiopod, the Lamellibranch, and in Pleurobranchus. It is for future research to show how far this condition of the renal organ extends throughout the Mollusca.

The renal organ in the Cephalopod differs from that of the Nudibranch chiefly by being more extensively developed. This is more particularly the case with respect to the genital chamber, which frequently contains many organs. The homologous chamber in the Nudibranch contains always, and never anything more than, the heart. In both

voL. XXIV. 
cases, however, the function is apparently the same. The renal chamber proper, in the two groups, is characterized by its glandular nature. In the Cephalopods the renal glands are specialized in connexion with the venæe cavæ, the rest of the chamber being for the purpose of receiving the extravasated fluids from the contained organs. In the Nudibranchs this chamber is modified both in its form and function. In some it is reduced to a delicately branched gland, and is consequently a mere secreting organ; in others it is partly glandular and partly a receptacle for extravasated fluids, either from the organs with which it is connected or from vascular ramifications that are spread over its walls.

Such being the condition of the renal organs in these two groups of mollusks, it seems evident enough that they are not designed for the reception of water from the exterior ; and indeed in neither the Cephalopod nor the Nudibranch could it possibly penetrate further than the first or renal chamber, as the passages connecting it with the other chamber in both these forms would be closed on the slightest pressure of the contained fluid, much in the same manner that the ureters are in the bladder of the higher animals. Fluid, however, may be easily made to pass in the contrary direction, namely, from the genital chamber in the one, or from the pericardial chamber in the other, to the renal chamber, and hence to the exterior through the external orifices. Thus an irresistible inference is raised in favour of the view that these chambers are for the purpose of throwing fluid out of the system, not for the purpose of taking it in.

Should there therefore exist any water-system as generally understood in these Mollusks, it is not in connexion with the renal organs. Some special apparatus may be provided for such a purpose; but if so, it has hitherto escaped my observation. At the same time the possibility of something of the kind must be allowed since the discovery that in at least Pleurobranchus the blood-vascular system opens externally: in this highly organized mollusk the external water ean apparently be drawn in and mingled directly with the circulating nourishing fluid. I have searched in vain, however, for a similar opening in the Nudibranchs; and until such be found, it may be fairly assumed that the fluid which pervades the tissues of these animals, as it does the tissues of all mollusks, is admitted in the ordinary way through the agency of the alimentary tube.

\section{EXPLANATION OF THE PLATES.}

The following letters indicate the same parts in all the figures:-

$a$, the so-called pericardium; $a^{\prime}$, dorsal wall of ditto; $a^{\prime \prime}$, floor of ditto; $b$, ventricle; $c$, auricle ; $d$, pyriform vesicle; $e$, orifice of ditto leading into pericardium; $f$, laminated plicæ in the interior of the vesicle; $g$, glandular appendages lining the tubular prolongation of ditto; $h$, tubular prolongation of ditto; $i$, orifice of prolongation, leading into the renal chamber; $i$, similar orifice at the apex of the vesicle when the prolongation is wanting; $j$, renal chamber proper; $j^{\prime}$, dorsal wall of ditto ; $k$, anterior bifurcation of ditto ; $l$, lateral branches of ditto; $m$, artery 
running in the wall of the branches; $n$, aorta; $o$, hepatic artery; $p$, openings of small branches of the renal chamber that penetrate the liver; $q$, hepatico-branchial vein; $r$, external orifice of the renal chamber; $s$, anal nipple; $t$, intestine; $u$, liver.

\section{Plate LIV.}

Fig. 1. General view of the viscera of Doris tuberculata, the dorsal skin having been laid open so as to exhibit the pericardium: $a$, the so-called pericardium laid open; $a^{\prime}$, dorsal wall of ditto; $b$, ventricle; $c$, auricle; $d$, pyriform vesicle seen through the floor of the pericardium; $e$, orifice of the resicle leading into ditto; $j$, renal chamber seen through the floor of ditto; $k, k$, right and left branch of the anterior bifurcation of the renal chamber; $l$, lateral branches of ditto; $m$, arteries running in the dorsal wall of the branches; $n$, aorta; $t$, intestine; $u$, liver; $v$, stomach; $w$, buccal organ; $x$, reproductive organs; $y$, gland connected with the vascular system; $z$, cerebral ganglia.

Fig. 2. Dorsal view of the liver-mass of the same, showing the renal chamber proper laid open, the pericardium and heart having been removed: $d$, pyriform vesicle; $e$, orifice of ditto, leading into the pericardium; a shred of the floor of the pericardium is attached round the orifice; $h$, tubular prolongation of the vesicle; $i$, orifice of ditto, leading into the renal chamber; $j$, renal chamber; $j^{\prime} j^{\prime}$, dorsal wall of ditto, laid open; $k$, anterior bifurcation of ditto; $l l$, lateral branches of ditto ; $m m$, arteries running in the dorsal wall of the branches; $n$, aorta ; $p$, openings of small branches that penetrate the liver; $q$, hepatico-branchial vein, covered with glandular matter, and receiving numerous branches on each side ; $r$, external orifice of the renal chamber ; $s$, anal nipple; $t t$, intestine cut through; $u$, liver; $v$, stomach ; $w$, reproductive organs ; $x$, branchial plumes.

Fig. 3. Renal chamber of Doris pilosa, laid open from above: $d$, pyriform vesicle, with a fragment of the pericardial floor attached to the broad end; $e$, orifice of the vesicle leading into the pericardium; $i^{\prime}$, orifice at the apex of the vesicle leading into the renal chamber; $j$, renal chamber proper, laid open; $j^{\prime} j^{\prime}$, dorsal wall of ditto turned back; $q$, hepatico-branchial vein; $r$, external orifice of the renal chamber; $s$, anal nipple; $t$, intestine; $u$, liver; $v$, branchial plumes.

Fig. 4. Dorsal view of the viscera of Pleurobranchus*, with the renal chamber laid open: $a$, the socalled pericardium; $a^{\prime \prime}$, floor of ditto; $b$, ventricle turned back, the aorta having been cut through; $c$, auricle; $d$, pyriform vesicle lying below, and opening through, the floor of the pericardium; $h$, tubular prolongation of the vesicle; $i$, orifice of the prolongation, opening into the renal chamber; $j$, renal chamber $; j^{\prime} j^{\prime}$, dorsal wall of ditto, laid open; $n$, entargement at the root of the aorta; $u$, liver-mass; $v$, salivary gland, with the posterior portion turned forward to expose the liver-mass; $w$, gland in connexion with the blood-system; $x$, cerebral ganglia.

Fig. 5. Pyriform vesicle of Tritonia Hombergii, laid open : $e$, orifice leading into pericardium; $f$, laminated plicæ; $g$, glandular appendages of the tubular prolongation.

Fig. 6. One of the laminated plicæ, removed, and much magnified: $v$, extremity attached to the margin of the orifice; $w$, vibratile cilia; $x$, a portion of the ciliated epithelium turned over to show the base of the cells from which the cilia arise.

Fig. 7. A much magnified portion of the glandular appendages from the tubular prolongation of the vesicle.

Fig. 8. A few of the granular cells from ditto, highly magnified.

* The species dissected was brought from Madras by Mr. Elliot, to whom we are indebted for so many interesting Nudibranchs. It is about an inch and a half long, of a roundish form, and of a delicate yellowish-white colour, with the upper surface reticulated with dark brown. It is probably undescribed. 


\section{Puate LV.}

Fig. 1. Posterior portion of Doridopsis tuberculosa, laid open, the heart removed, and the interior of the renal chamber exposed to view: $a$, the so-called pericardium; $a^{\prime} a^{i} a^{t}$, dorsal wall of ditto, turned back; $a^{\prime \prime} a^{\prime \prime} a^{\prime \prime}$, portions of the floor of ditto; $b$, ventricle turned forward; $d$, pyriform vesicle; $e$, orifice of ditto, leading into pericardium; $i^{\prime}$, orifice at the apex of the vesicle, leading into the renal chamber; $j j$, renal chamber laid open; $j^{\prime} j^{\prime}$, dorsal wall of ditto, opened and reflected; $o o$, hepatic arteries; $p$, orifices of small branches of the renal chamber, that penetrate the liver; $q$, hepatico-branchial vein; $r$, external orifice of the renal chamber; $s$, anal nipple; $t$, intestine; $u u$, liver; $v$, skin of the animal ; $w$, branchial plumes.

Fig. 2. View of the renal chamber of Doridopsis clavulata, laid open : $d$, pyriform vesicle, with a little of the pericardial floor attached to the broad extremity; $e$, orifice of ditto, leading into the pericardium; $i^{\prime}$, orifice at the apex of ditto, leading into the renal chamber; $j j$, renal chamber; $j^{\prime} j^{\prime}$, dorsal wall of ditto, reflected; 0 , hepatic artery; $p$, orifices of small branches of the renal chamber, penetrating the liver; $q$, hepatico-branchial vein; $r$, external orifice of the renal chamber.

Fig. 3. Pyriform vesicle of Doridopsis gemmacea, laid open to show the laminated plicæ: $e$, orifice communicating with the pericardium; $i^{\prime}$, orifice at the apex of the vesicle, opening into the renal chamber; $f$, laminated plicæ.

Fig. 4. A few of the cilia, much enlarged, from the laminated plicæ of Tritonia Hombergii: $v$, ovate granular vesicle at the base of the cilium; $w$, several of the cilia adhering together ; $x$, surface of attachment.

Fig. 5. Lateral view of the viscera of Plocamophorus Ceylonicus, exhibiting the renal organ in its natural position: $a^{\prime \prime}$, floor of the pericardium, turned to one side; $b$, ventricle seen through, ditto, giving off aorta and hepatic artery; $c$, auricle; $d$, pyriform vesicle attached to the floor of the pericardium, through which it opens; $j$, renal chamber reduced to a cæcal tube; $r$, external orifice of ditto; $r^{\prime}$, tube leading from ditto to the renal chamber; $q$, hepatico-branchial vein laid open, showing three large orifices leading into the branchial plumes; $s$, anus ; $t$, intestine ; $u u$, the two lobes of the liver; $v$, first stomach; $w$, buccal organ; $x$, salivary gland; $y$, reproductive organs; $z$, cerebral ganglia.

\section{Plate LVI.}

Fig. 1. View of the posterior portion of Hexabranchus gloriosus $*$, the dorsal skin removed, and the pericardium laid open : $a^{\prime} a^{\prime} a^{\prime}$, dorsal wall of pericardium, turned back; $a^{\prime \prime} a^{\prime \prime}$, floor of ditto, laid open to show the renal chamber; $b$, ventricle turned forward, with a portion of the auricle attached; $c c c$, portions of the auricle; $d$, pyriform vesicle; $e$, orifice of ditto, leading into the pericardium; $j$, renal chamber; $q$, hepatico-branchial vein; $r$, external orifice of the renal chamber; $s$, anal nipple; $u u$, liver; $v$, branchial plumes; $w$, margin of the foot; $y y$, dorsal skin.

Fig. 2. Dorsal view of the liver-mass of the same, the pericardium entirely removed, and the renal chamber laid open : $b$, ventricle, turned forward; $d$, pyriform vesicle, with a shred of the pericardial floor adhering to the broad extremity; $e$, orifice of the vesicle leading into the pericardium; $h$, tubular prolongation of ditto; $i$, orifice at the extremity of the prolongation ; $j j$, renal chamber, laid open; $j^{\prime} j^{\prime}$, dorsal wall of ditto, turned back; $l^{\prime}, l$, openings of lateral branches that follow the principal arteries ramifying over the liver; $n$, aorta; $o o$, hepatic arteries; $p p$, openings of small branches of the renal chamber that penetrate the liver; $q$, hepatico- 
branchial vein; $r$, external orifice of the renal chamber laid open; $t$, intestine; $u$, liver; $v$, portion of the stomach.

Fig. 3. Pyriform vesicle and prolongation laid open: $d$, vesicle; $e$, orifice of ditto leading into pericardium, with a shred of the pericardial floor attached ; $f$, laminated plicx; $g$, glandular dendritic appendages lining the interior of the prolongation; $h$, prolongation; $j j$, renal chamber, laid open ; $j^{\prime} j^{\prime}$, dorsal wall of ditto, turned back.

Fig. 4. Much-enlarged view of three of the dendritic tufts or processes from the interior of the tubular prolongation.

\section{Plate LVII.}

Fig. 1. Dorsal view of the viscera of Bornella digitata, exhibiting the renal chamber undisturbed: $a$, the so-called pericardium, turned to one side; $b, c$, ventricle and auricle seen through the floor of ditto; $d$, pyriform vesicle, opening through ditto, ditto; $j j$, renal chamber; $k$, anterior bifurcation of ditto; $l l$, lateral branches of ditto; $r$, external orifice of ditto; $r^{\prime}$, tube leading from ditto to ditto; $s$, anal nipple; $t$, intestine; $u$, rudimentary liver, or central portion of the gastro-hepatic system; $v v$, lateral branches of ditto supplying the dorsal papilla; $v^{\prime}$, branchlets of the renal organ ramifying over ditto; $w$, ovary; $x$, salivary glands; $y$, buccal organ; $z$, cerebral ganglia.

Fig. 2. Renal chamber of the same, removed, with the lateral branches spread out: $d$, pyriform vesicle, with a portion of the pericardial floor attached; $e$, orifice of ditto, leading into the pericardium; $j j$, renal chamber; $k k$, right and left branch of the anterior bifurcation of ditto; $l l$, lateral branches of ditto; $r$, external orifice of ditto; $r^{\prime}$, tube leading from ditto to ditto; $s$, anal nipple.

Fig. 3. Pyriform vesicle, more highly magnified: $d$, vesicle, with a shred of the pericardial floor adhering to the broad extremity; $e$, orifice of ditto, leading into the pericardium; $i^{\prime}$, orifice at the opposite extremity of ditto, leading in to the renal chamber; $j$, renal chamber laid open; $k, k$, branches of the anterior bifurcation of ditto; $l$, lateral branches of ditto; $r$, tube leading to the external orifice of ditto.

Figs. 4 \& 5. Much-enlarged views of two of the lateral branches of the renal chamber: $v$, root of the branch; $w w w$, enlarged cæcal extremities of ditto.

Fig. 6. The so-called pericardium, laid open: $a^{\prime}$, dorsal wall of the pericardium; $a^{\prime \prime}$, floor of ditto; $b$, ventricle; $c$, auricle; $d$, pyriform vesicle seen through the auricle and floor of the pericardium; $r$, external orifice of the renal chamber; $s$, anal nipple.

\section{Plate LVIII.}

Fig. 1. Dorsal view of the viscera of Scyllea marmorata, the heart and pericardium having been removed: $c c c$, fragments of the auricle; $d$, pyriform vesicle; $e$, orifice of ditto leading into the pericardium; $j j$, anterior and posterior branches of the renal chamber reduced to mere tubes, giving off numerous ramuscules to the various organs; the anterior extremity of the anterior branch is seen ramifying in front of the intestine; $l^{\prime}$, gastric and hepatic ramuscules; $l^{\prime \prime}$, large branch to the underside of the stomach; $l^{\prime \prime \prime}$, branches to the underside of the liver; $l^{\prime \prime \prime \prime} l^{\prime \prime \prime \prime} l^{\prime \prime \prime \prime}$, ovarian ramuscules; $r$, external orifice of the renal chamber; $r^{\prime}$, tube leading to ditto; $s$, anal nipple; $t t^{\prime}$, intestine, with a branch of the renal organ ramifying over it; $u$, liver-masses; $v v v$, ovarian masses; $v^{\prime}$, oviduct; $w$, anterior stomach, or crop; $y$, reproductive organs; $z$, buccal organ; $z^{\prime}$, cerebral ganglia.

Fig. 2. Pericardium of the same, laid open : $a^{\prime} a^{\prime}$, dorsal wall of the pericardium turned back; $a^{\prime \prime}$, floor of ditto; $b$, ventricle; $c$, auricle; $d$, pyriform vesicle, opening through the floor of the pericardium. 
Fig. 3. Ovarian ramuscule of the renal chamber, much enlarged: $v$, ovarian mass; $w$, branch connecting the ramuscule with the posterior trunk of the renal chamber.

Fig. 4. A portion of one of the hepatic ramuscules, greatly enlarged.

Fig. 5. Three of the granular cells from the glandular matter lining the ramuscule, greatly magnified.

Fig. 6. Anal nipple: $r$, external orifice of the renal chamber; $v$, anal orifice.

\section{Plate LIX.}

Fig. 1. Diagram of lateral view of the viscera of Doris tuberculata, exhibiting the relative position of the renal chambers : $a$, so-called pericardium; $a^{\prime}$, dorsal wall of ditto; $a^{\prime \prime}$, floor of ditto; $b$, ventricle; $c$, auricle; $d$, pyriform vesicle; $e$, orifice of ditto, opening into the pericardium; $h$, tubular prolongation of vesicle; $i$, orifice of ditto, leading into the renal chamber $; j j$, renal chamber proper $; j^{\prime}$, dorsal wall of ditto; $k k$, branches of the anterior bifurcation of ditto; $l$, lateral branches of ditto; $r$, external orifice of ditto; $s$, anal nipple ; $t t$, intestine ; $u$, liver ; $v$, stomach ; $w$, œsophagus; $x$, buccal organ; $x^{\prime}$, oral orifice; $y$, ventral surface or foot of the animal; $z$, dorsal surface.

Fig. 2. Diagram of lateral view of the viscera of Eledone cirrosus, to show the homological relation of the renal chambers to those of Doris.

(The letters in this instance in no way correspond to those of the other figures.)

$a$, renal chamber proper, the so-called pericardium; $b$, external orifice of ditto; $c$, genital chamber, the homologue of the so-called pericardium in Doris; $d$, ovary; $e$, tube connecting the genital chamber with the renal chamber proper; $f$, orifice of ditto, leading into genital chamber; $g$, orifice at the other extremity of the tube, leading into the renal chamber; $h$, systemic ventricle; $i$, oral orifice; $j$, buccal organ; $k$, œsophagus; $l$, crop, or anterior stomach; $m$, stomach or gizzard; $n$, spiral cæcum of ditto; $o$, intestine; $p$, anal nipple; $q$, biliary ducts; $r$, liver ; $s$, duct of the ink-bag; $t$, branchial chamber ; $u$, funnel ; $v$, portion of two of the arms. 


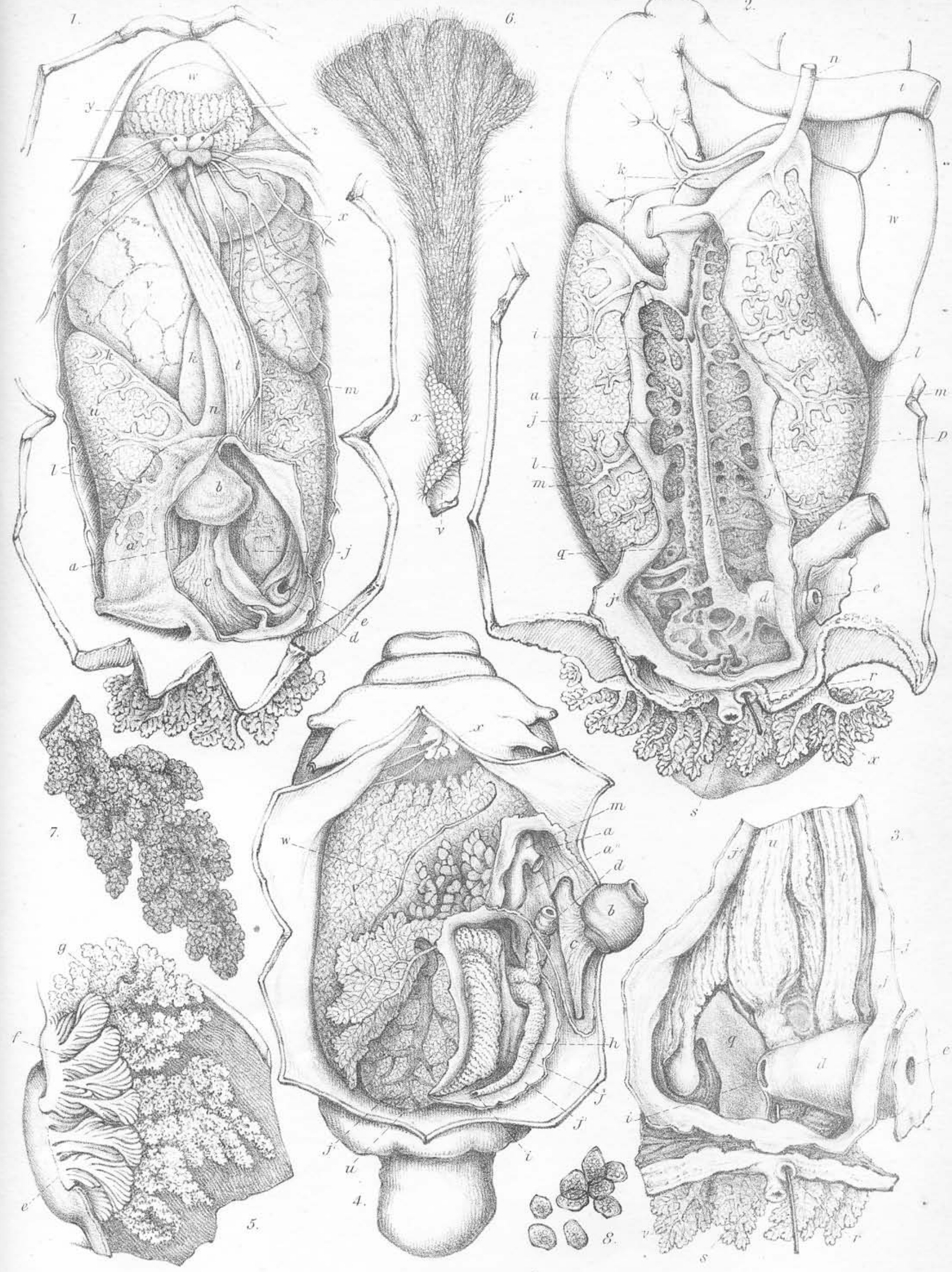




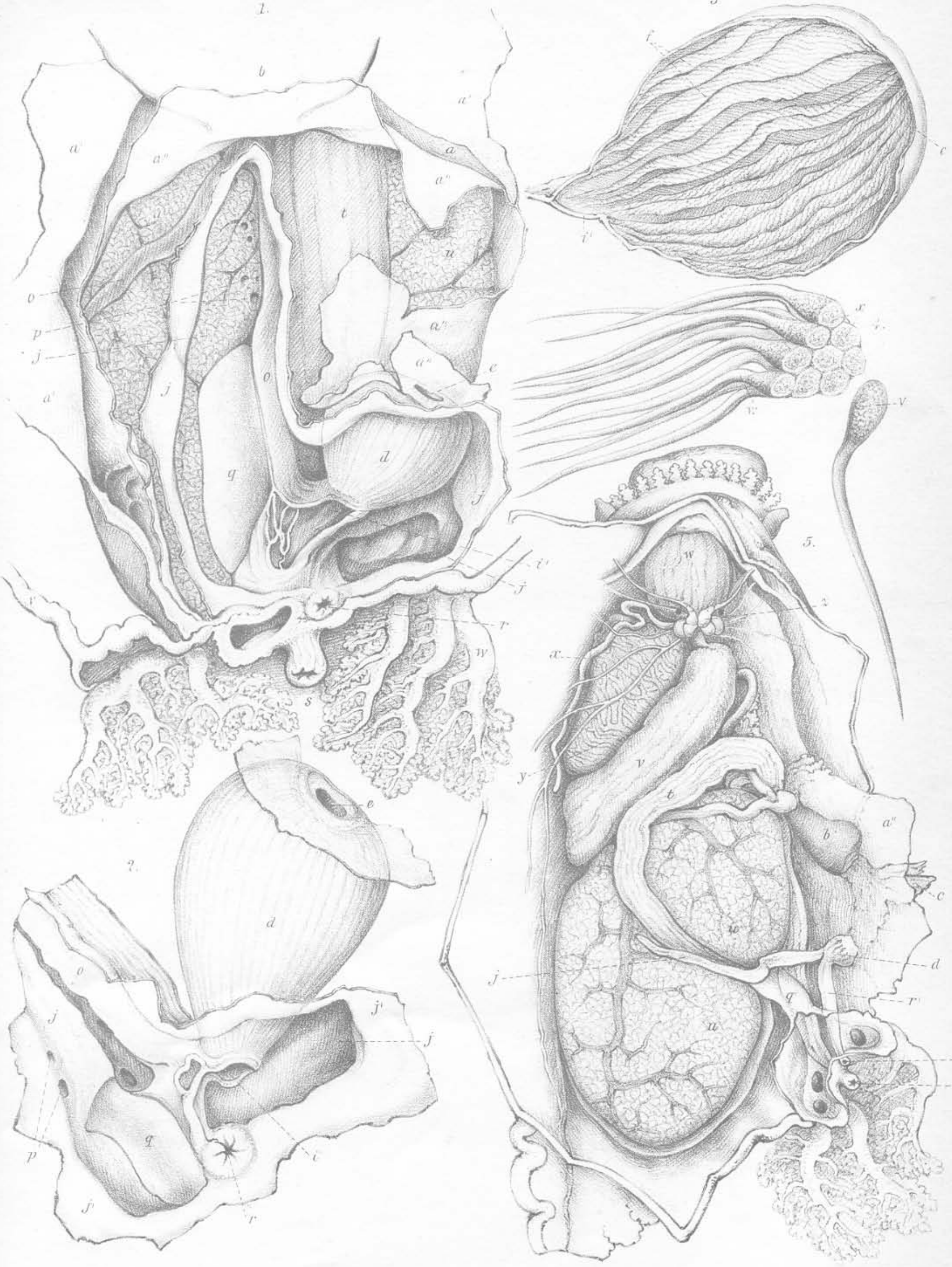




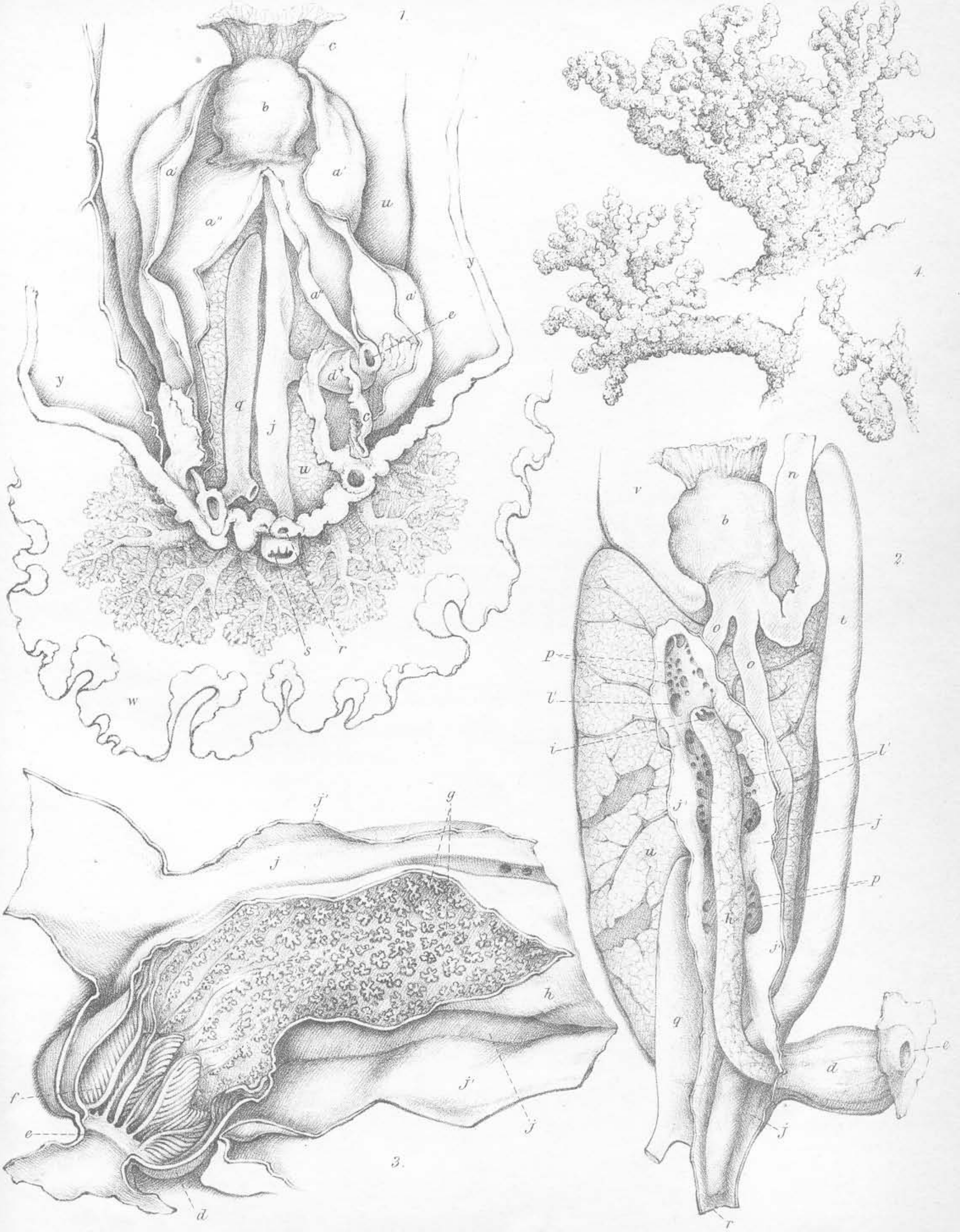




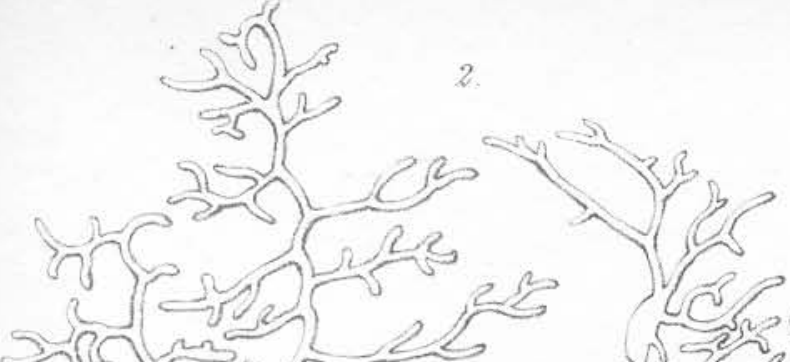

sis oncer 0 Gen

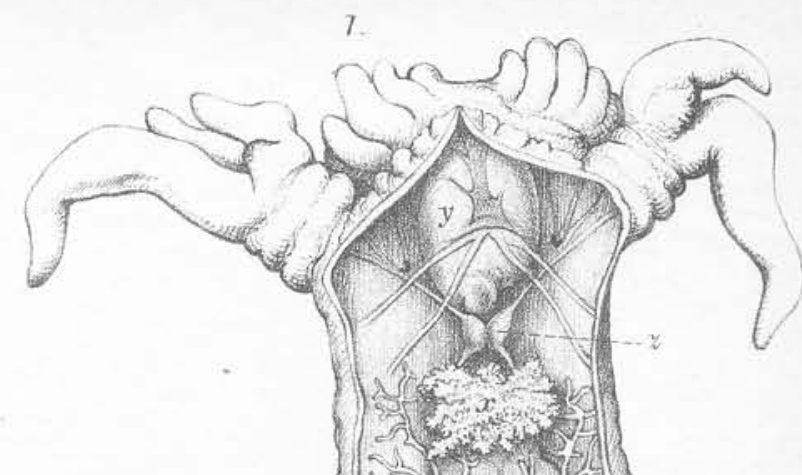

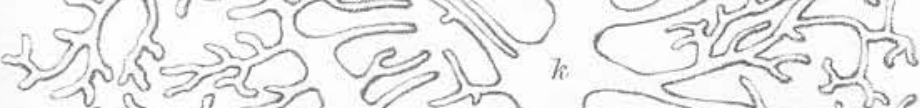
की

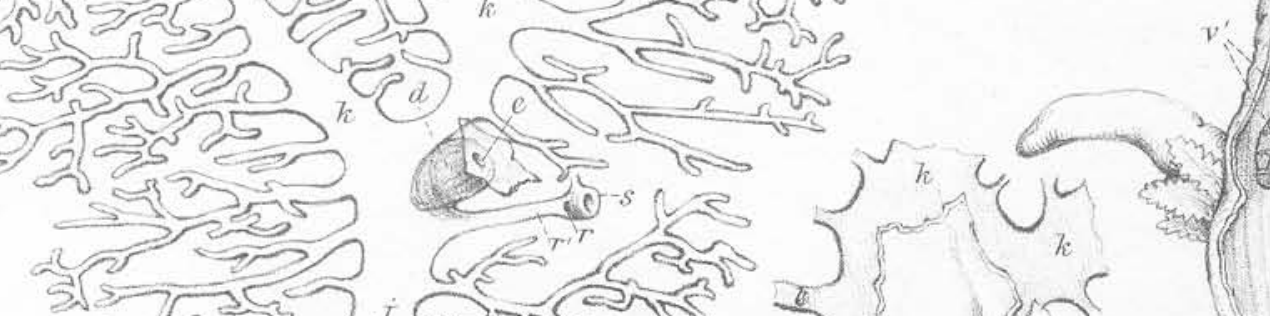
ing

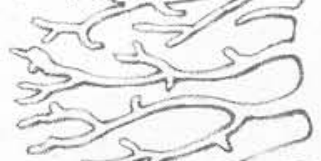

s?

sis

र्ये

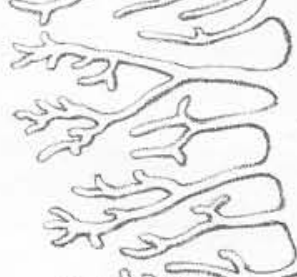

कोत

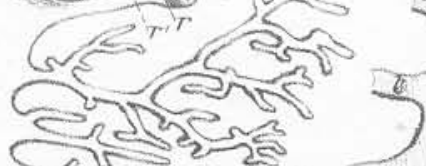

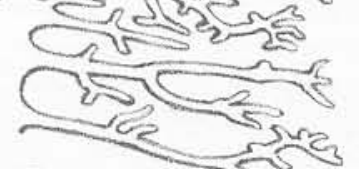

किe $\sqrt{2 \sqrt{2}}$ 525 रूतs 7

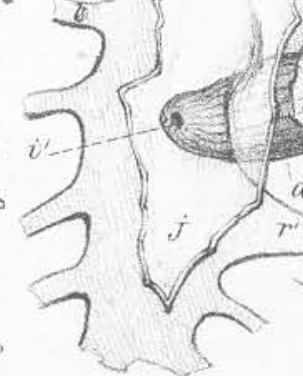
sonstis
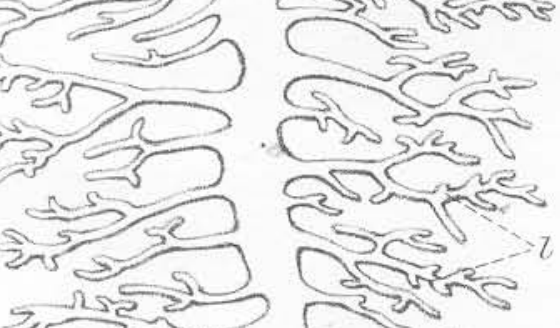

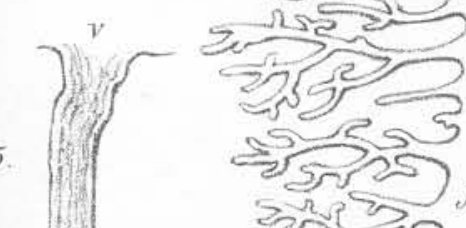
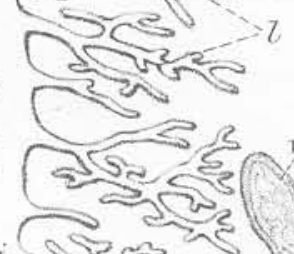
$j$ करित्ड

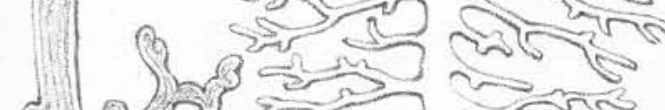

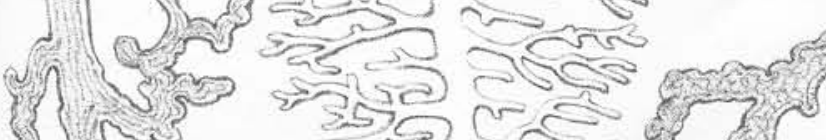

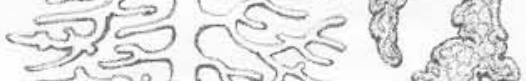

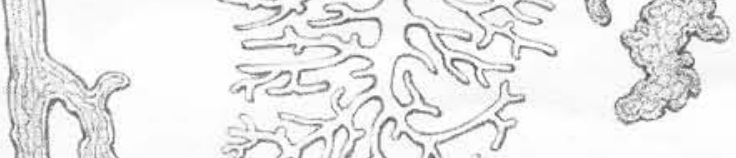
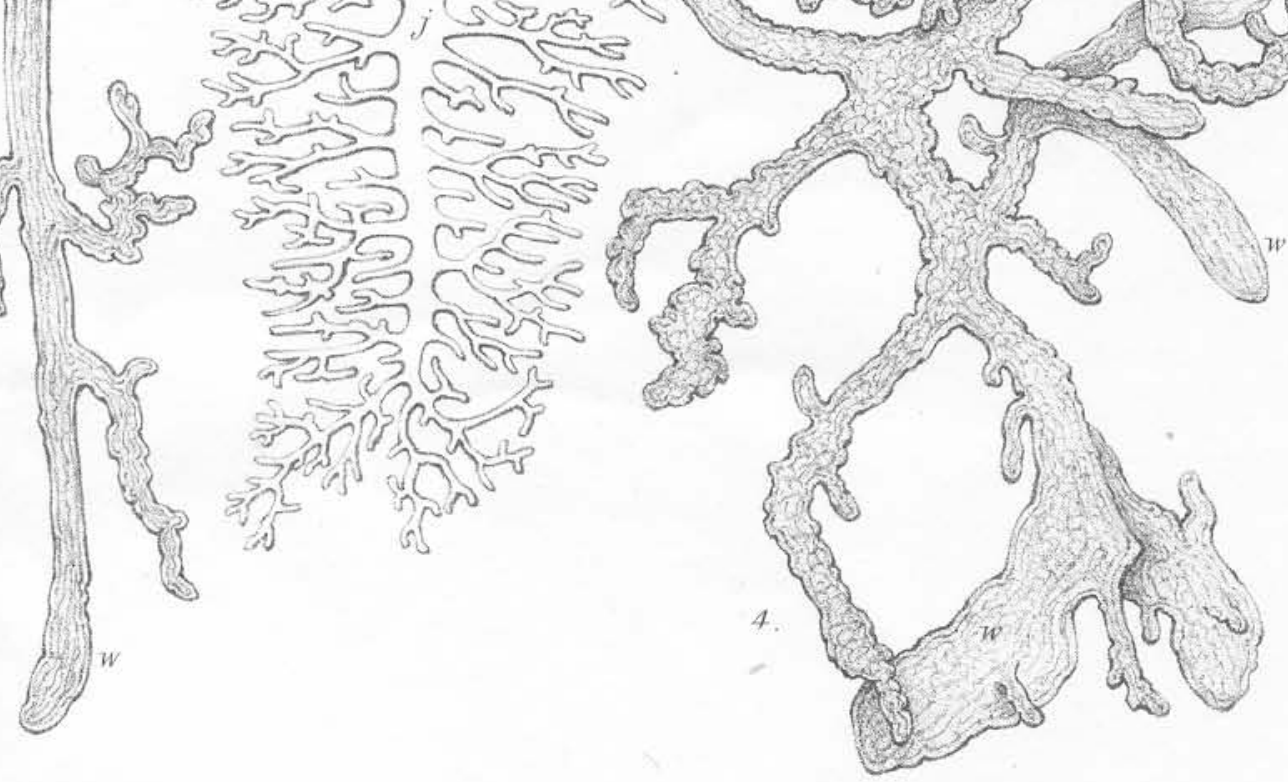

3.

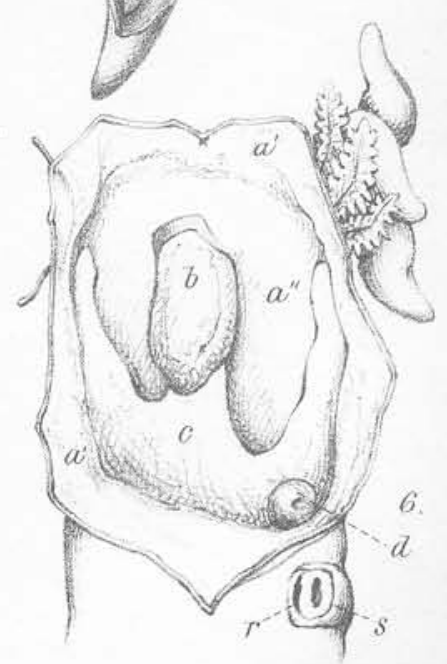




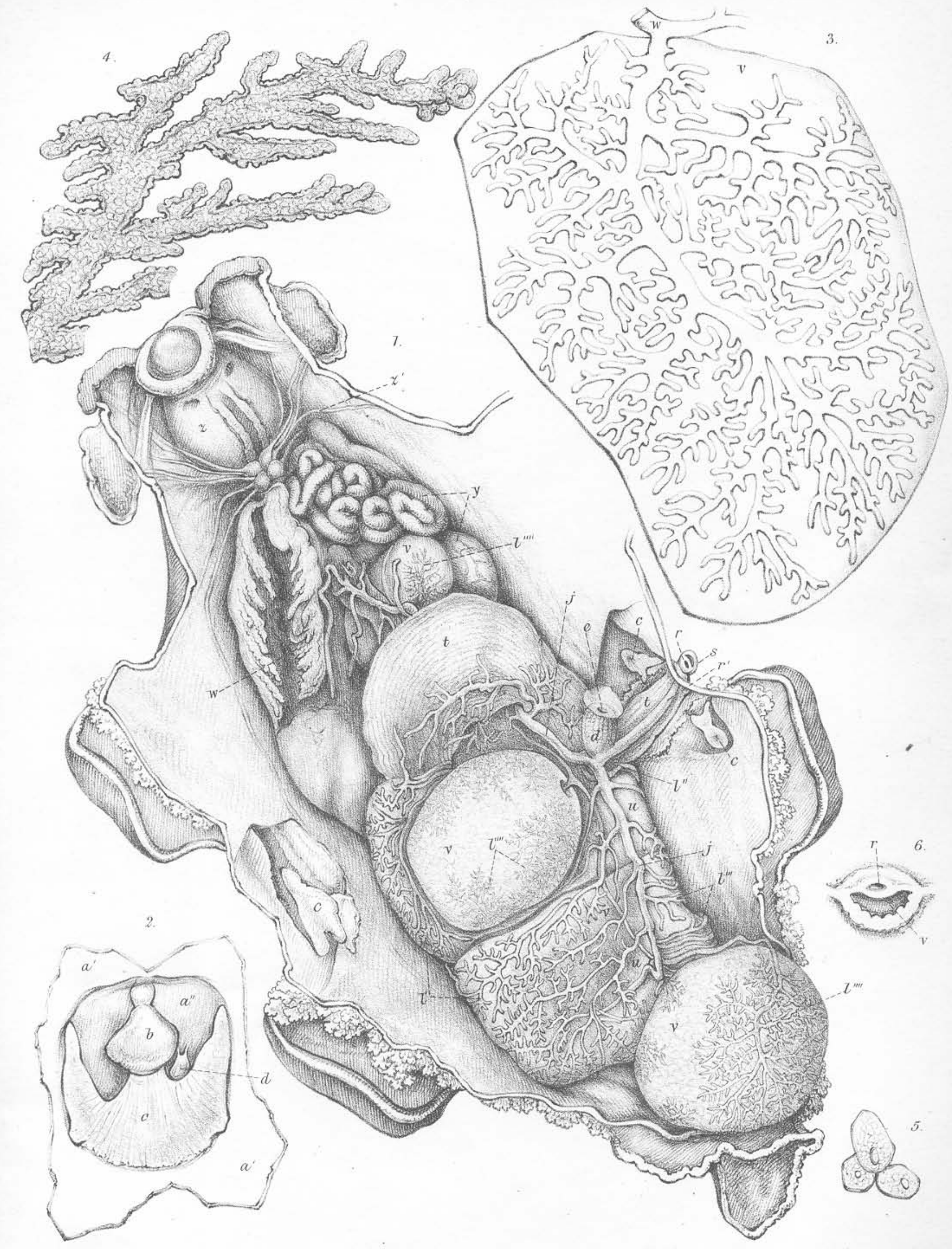



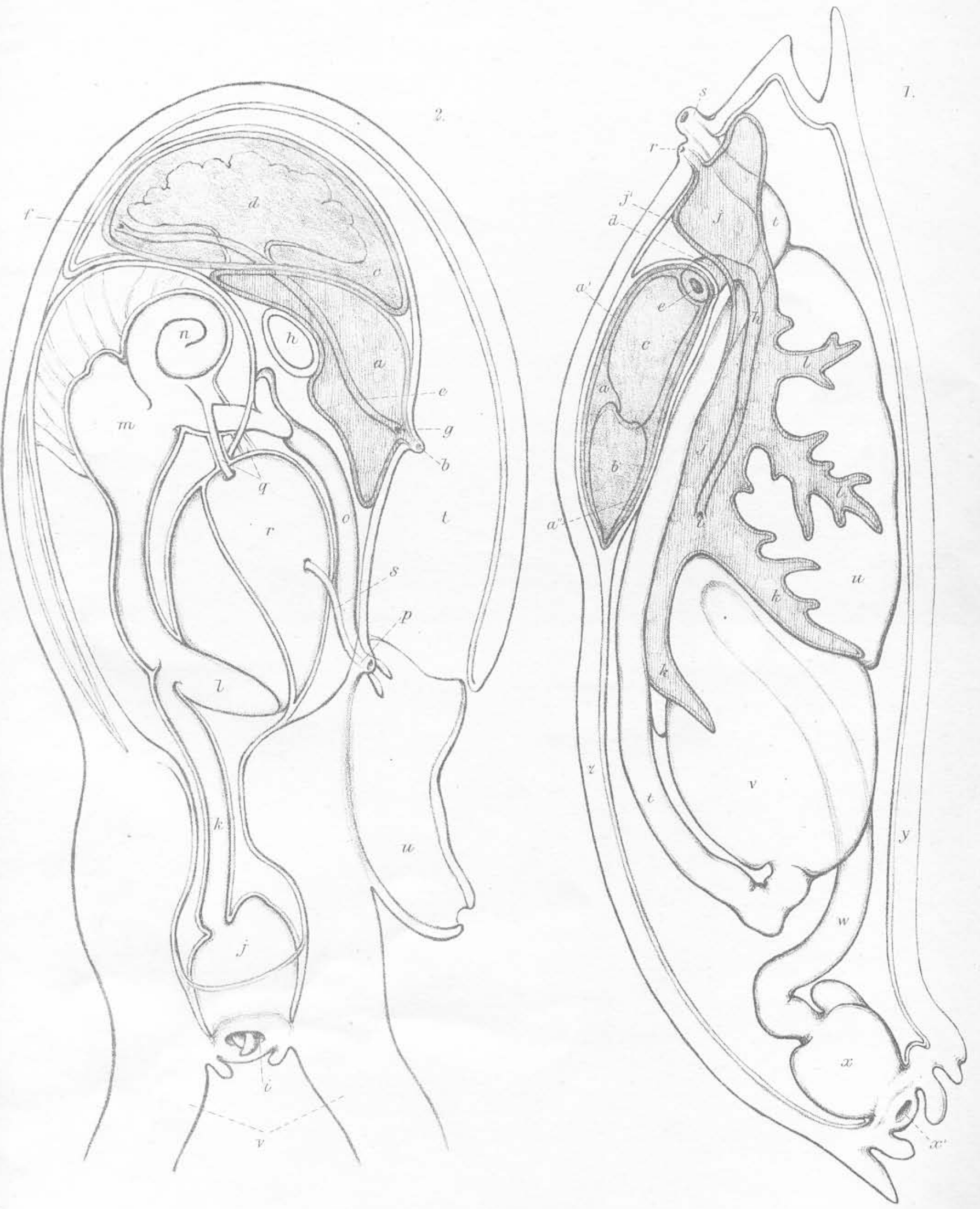